\title{
Space Operations for a New Era of Exploration Launch Vehicles
}

\author{
Daniel J. Davis, Vehicle Integration Manager \\ NASA Ares Projects Office, Marshall Space Flight Center, AL, 35812
}

\begin{abstract}
Since 2005, Ares has made substantial progress on designing, developing, and testing the Ares I crew launch vehicle and has continued its in-depth studies of the Ares V cargo launch vehicles. The combined Ares I/Ares $\mathrm{V}$ architecture was designed to reduce the complexity and labor intensity of ground operations for America's next journeys beyond low-Earth orbit (LEO). The Ares Projects' goal is to instill operability as part of the vehicles' requirements development, design, and operations. Since completing the Preliminary Design Review in 2008, work has continued to push the Ares I beyond the concept phase and into full vehicle development, while tackling fresh engineering challenges and performing pathfinding activities related to vehicle manufacturing and ground operations.
\end{abstract}

\section{Introduction}

Qince the completion of the Ares I Preliminary Design Review (PDR) in September 2008, the team has continued to refine the design of the Ares I launch vehicle, with a focus on delivering a safe, affordable launch vehicle that meets the requirements of Constellation's mission. In the past year, the project has achieved several major testing milestones, including the first firing of a five-segment solid rocket motor built to Ares Projects specifications, the drop test of a full first-stage main parachute cluster, extensive development of upper stage manufacturing capabilities and processes, and the launch of the Ares I-X flight test vehicle.

\section{A Year of Progress}

As part of the ongoing maturation of the Ares I design, engineers have continued a range of wind tunnel testing over the past year. Tests have covered every aspect of Ares I operations, from sitting on the launch pad through ascent, stage separation, and reentry of the first stage. To date, over 7,500 hours of wind tunnel tests have been conducted, with models of increasing fidelity. Data from these tests help engineers refine the design of the vehicle and provide increased maturity to the loads databases used to fine tune Ares I performance. Renovations continued this year on the historic Dynamic Test Stand at Marshall Space Flight Center (MSFC), as construction crews removed platforms originally installed to support ground vibration testing of the Space Shuttle. Installation of movable platforms and support structures will allow ground vibration testing of full-scale Ares I hardware, while providing flexibility to test the Ares $\mathrm{V}$ and other vehicles in the future. Extensive vehicle design has been documented in 3-D CAD model and specification. Producibility and manufacturing plans based on electronic Model-Based Instruction been have developed and tooling and fixtures are designed and in fabrication.

\section{A. First Stage Progress}

The Ares I First Stage team conducted two major hardware tests last year, starting with a main parachute cluster drop test in May 2009 at Yuma Proving Grounds, AZ. The main parachutes -- the largest rocket parachute ever manufactured - measure 150 feet in diameter and weigh 2,000 pounds each. They serve as the central element of the rocket's deceleration system, which includes a pilot parachute, a drogue parachute and the main parachutes. Deployed in a cluster, the main parachutes open at the same time, providing the drag necessary to slow the descent of the huge solid rocket motor for a soft landing in the ocean. This was the eighth in an ongoing series of flight tests supporting development of the Ares I parachute recovery system. Researchers dropped the 41,500-pound load from a U.S. Air Force C-17 aircraft flying at an altitude of 10,000 feet. The parachutes and all test hardware functioned properly and landed safely.

Development Motor 1 (DM-1), the first five-segment solid rocket motor built to Ares specifications, was testfired in September 2009. The firing was the culmination of a year-long effort by NASA and its industry partners 
ATK. The team collected data from 650 sensors to evaluate the motor's performance. Motor upgrades from a shuttle booster include the addition of the fifth segment, a larger nozzle throat, and upgraded insulation and liner. The forward motor segment also has been improved for performance by adding another fin, or slot in the propellant. This change in the geometry of the propellant provides additional surface area for burning the solid fuel, which results in greater thrust.

The DM-1 nozzle throat is three inches wider in diameter than the nozzle used for the shuttle. The bigger nozzle throat allows the motor to develop the additional thrust from the five-segment booster. It also meets NASA's structural requirements to stay within the pressure capacity of the existing steel cases -- the large, barrel-shaped cylinders that house the fuel -- ensuring safety and reliability. Upgrades also were made to the insulation and liner that protect the first stage's steel cases. The DM-1 static fire test and those that follow are essential to understanding as many aspects of the motor as possible, including strengths and weaknesses, and ultimately delivering the safest and most reliable motor possible. A second test motor, Development Motor 2, has been cast and a static firing is scheduled for the September 2010.

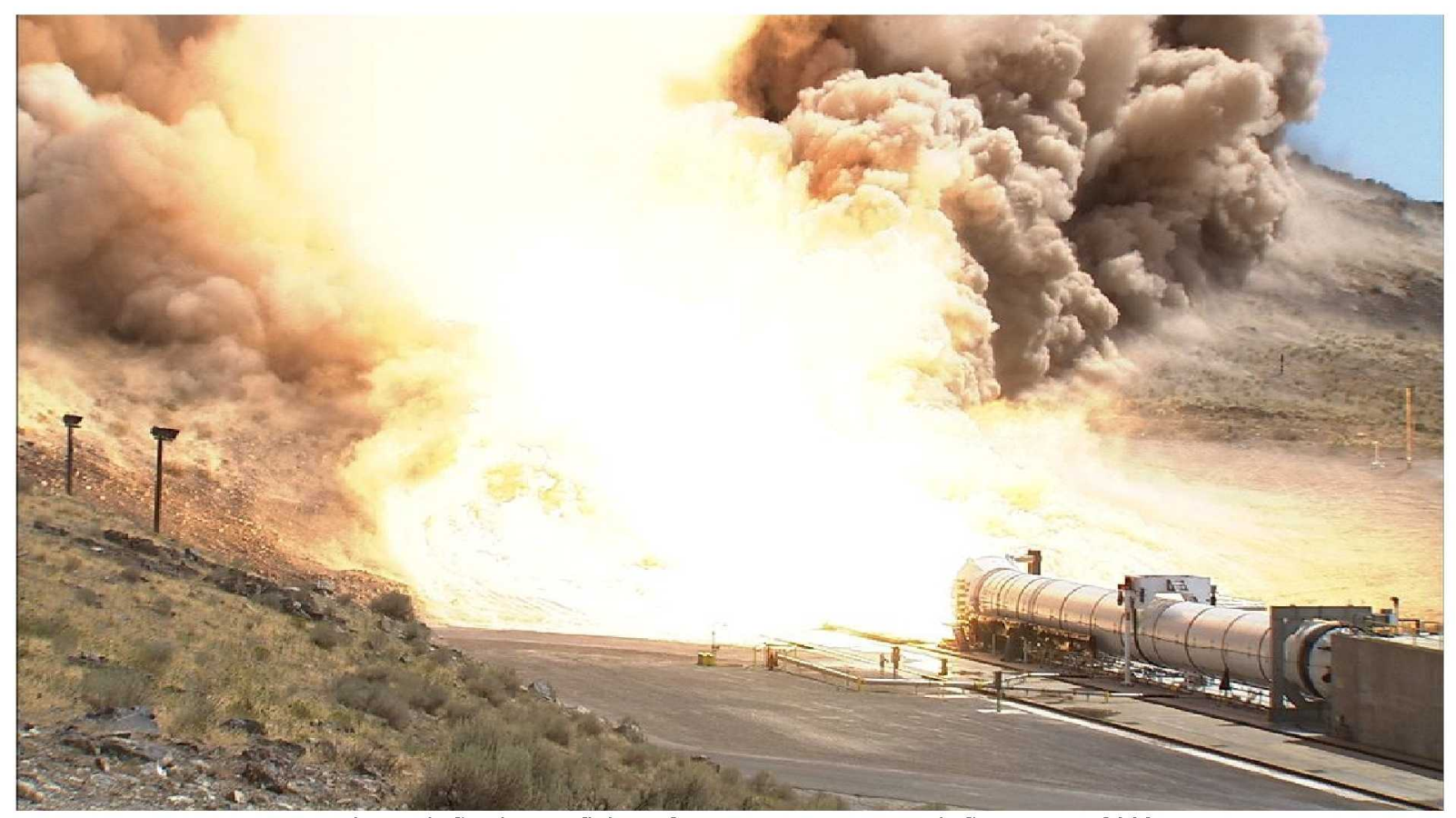

Figure 1. Static test firing of Development Motor 1, September 2009.

In terms of function, the first-stage avionics system will be similar to that of the Shuttle electrical system. Ares First Stage is however developing an entirely new avionics system that will use state of the art electronic technology and bring the new Ares vehicles in line with today's industry standards. The team is developing 6 line-replaceable units (LRUs) to control Ares first stage. These completely new LRUs will replace and perform the same functions as the now dated technology of Shuttle's two Integrated Electronics Assemblies (IEAs). The new LRU system will perform the same kinds of tasks of the IEAs in a similar order as with Shuttle. Component manufacture and testing of these new LRUs were conducted in early 2009. In addition to development of these avionics components, the team constructed a full-scale simulator of the Ares I first stage's forward structures, allowing for comprehensive testing of the avionics system in flight-like configuration. This allows the Ares team to test not only function of individual parts and the integrated system, but also the logistics and ground operations procedures that will be required to replace units during preflight operations.

\section{B. Upper Stage Progress}

The Upper Stage team conducted structural buckling tests on Ares I barrel panels this year, confirming predictions about the behavior of the aluminum-lithium panels under pressure. The purpose of these Shell Buckling tests was to characterize compression behavior of grid-stiffened panel design candidates, characterize panel stability, and allow correlation of analytical models. Using photogrammetry techniques, engineers applied pressure to the panels until they buckled and eventually crumpled. A series of black dots on the panels allowed high-speed video to 
show precisely where the panels begin to structurally fail. In the tests conducted in 2009 , the panels failed at loads in excess of those anticipated by the preliminary analysis, and in sequence as anticipated by computer modeling.

A candidate roll control thruster underwent hot-fire testing in 2009 at Aerojet in Sacramento, CA, demonstrating operation in pulse and sustained firing modes. During the hot-fire testing, the thruster demonstrated capability of over four times the required mission duration. Following the hot-fire test, the thruster was dismantled and dissected to study the effects of the firing. The 625-lbf monopropellant hydrazine thruster exhibited nominal and predicted performance in over 800 pulses and with over $1200 \mathrm{lbs}$ of propellant throughput, demonstrating a life capability of over four times the required mission duration. The thruster demonstrated a wide range of operability in both pulse mode and steady state operation. Duty cycles ranged from $1 \%$ to $100 \%$, with a minimum Electrical Pulse Width (EPW) of $100 \mathrm{msec}$ while maintaining thermal stability throughout. Several ambient temperature starts were completed to verify durability of the catalyst bed. A rigorous set of hot-restart scenarios were demonstrated to verify thermal margin against spontaneous and premature hydrazine decomposition. The thruster, tested with a VACCO valve developed under the NASA Design Team through Jacobs Engineering, showed no indication of adverse behavior. Knowledge gained from this initial testing will help engineers further refine the design for final flight hardware.

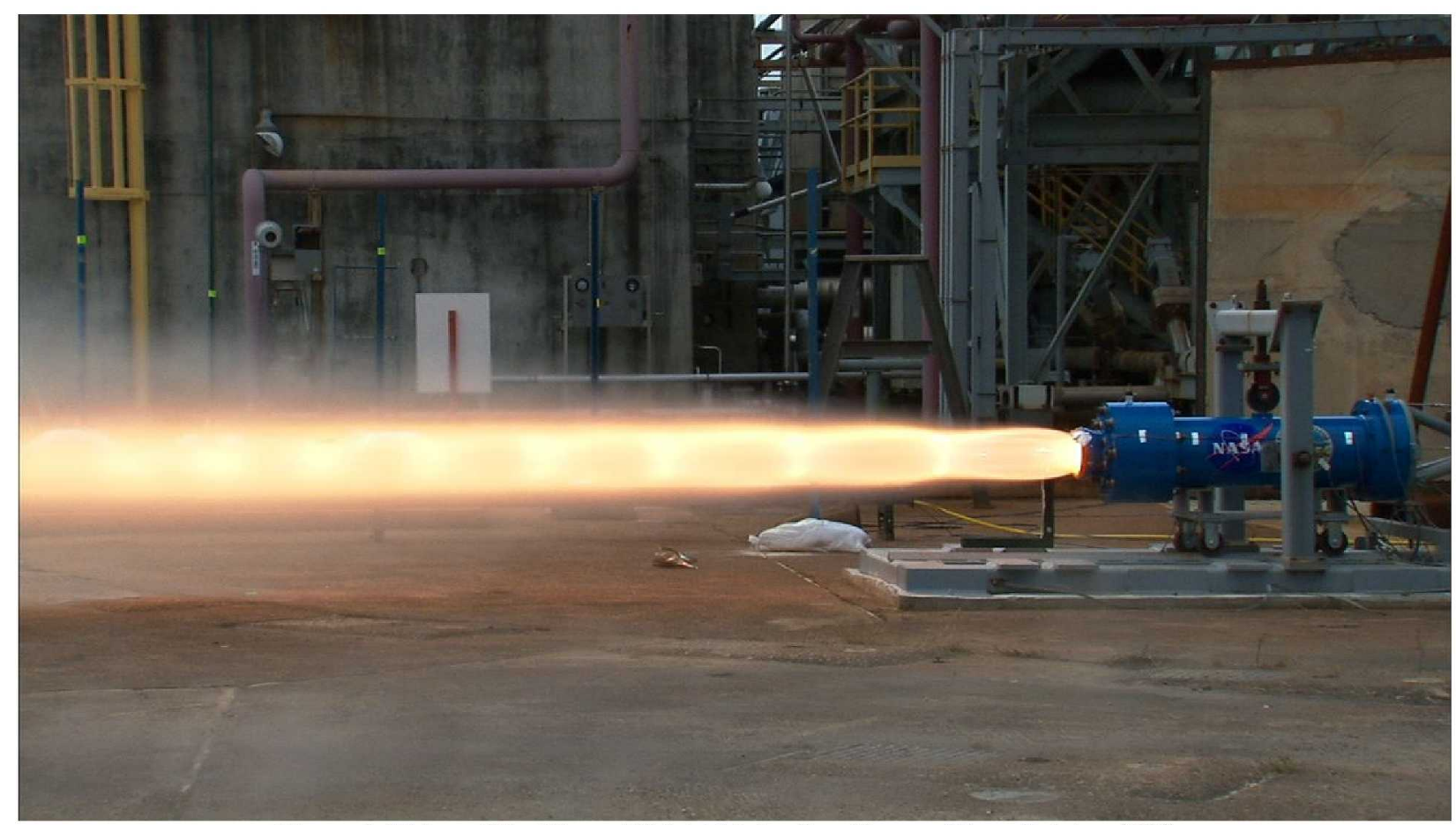

Figure 2. Firing of the Heavy Weight Motor for ullage settling, October 2009.

Two heavyweight solid motors were tested for use in ullage settling on the upper stage. The second Upper Stage Heavy Weight Motor (HWM) hot-fire test was successfully conducted on October 8, 2009 in MSFC Test Stand 116. The test further validated the performance of the Ullage Settling Motor (USM) propellant, propellant grain structure, and propellant geometry for the Ares I. The HWM insulated case and nozzle were provided by the U.S. Army's Aviation and Missile Research, Development, and Engineering Center (AMRDEC). Engineers used data collected from the first HWM test in September 2008 to modify the motor for this test. Instrumentation was also added to track motor performance by measuring acoustics and combustion stability. To keep test costs to a minimum, the Upper Stage USM subsystem coordinated with Redesigned Solid Rocket Motor and External Tank personnel last year to use existing facilities at Marshall for the USM motor fire tests. Test Stand 116 was upgraded with the newly developed USM Test Stand Adapter to accommodate the length of the USM. The Test Stand Adapter was designed by NASA and machined locally. In the final Ares I vehicle, these motors will fire to settle propellant in the upper stage prior to the altitude start of the J-2X engine.

\section{Upper Stage Engine Progress}


As part of the second ullage motor test, a series of candidate J-2X nozzle materials were positioned to approximate the plume impingement of the ullage motor during flight, providing engineers from the J- $2 \mathrm{X}$ team with valuable data to assist in down-selecting the final material to be used in coating the J-2X nozzle extension. In the 4second test, $4 \times 6$-inch panels of Haynes 230 nickel-based allow covered with the two coating candidates were set up 20 feet downstream and 20 inches off the centerline of the ullage motor plume, simulating the heating conditions that will be seen on the actual hardware.

Computer analysis indicated that the exhaust plume from these motors would impinge on the exterior of the nozzle extension. The motors use solid propellant, and the exhaust plume contains relatively large, high-speed particles, essentially grit-blasting any surface that it encounters. The test in October determined whether or not the plume byproducts would damage the nozzle extension's emissivity coating or affect the coating's ability to protect and dissipate energy from the metal extension. Post-test inspection showed that the coatings were still adhered to the Haynes 230 panels. There were no indications of erosion and no changes in pre- and post-test emissivity. There was some greenish brown particulate residue from the motor exhaust plume, but it didn't change the emissivity. Ares engineers plan to do one more similar series, this time using the orthogrid design of the actual nozzle extension, which may tend to 'pocket' the settling motor exhaust particles.

Testing also continued this year on the J-2X "workhorse" gas generator (GG). The workhorse gas generator is a hot-fire test article for the gas generator component that is so named because the test article structure is more beefedup so that it can survive an extended test program, which the expendable flight engine component is not designed to do. However, the workhorse precisely duplicates the flow passages of the flight hardware. The purpose of the Workhorse GG test program was to test various designs in order to choose the best configuration to meet engine requirements. Testing was also required for verification of component requirements that cannot be measured on a full engine test. The first series of Workhorse GG tests was completed in 2008 and helped engineers understand and prove the temperature uniformity and combustion stability of the J-2X gas generator design. Testing was conducted in Test Stand 116 at the Marshall Center. The initial test hardware arrived in March 2008. Installation and early checkout tests occurred in April and May. Testing concluded in September 2008.

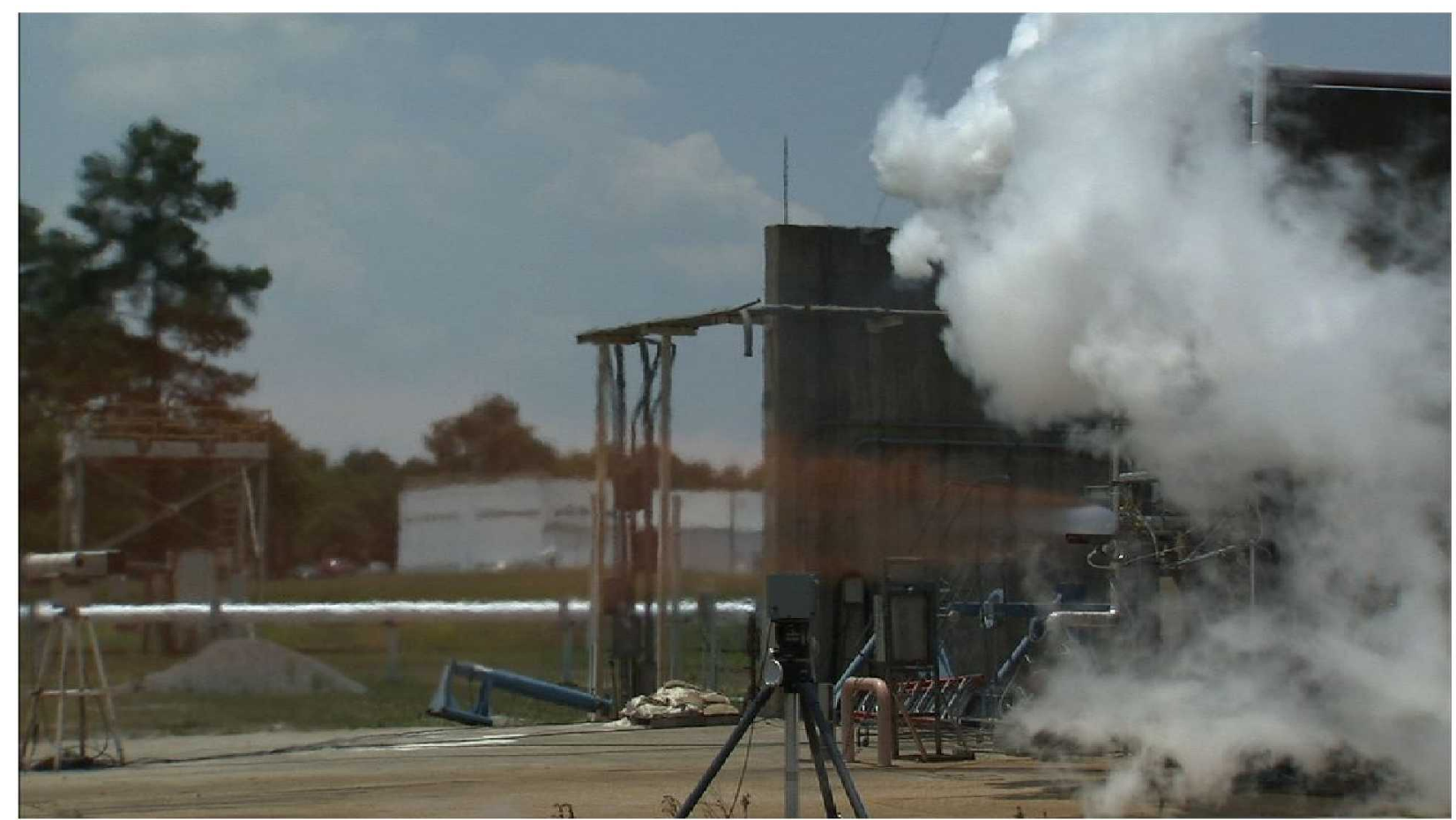

Figure 3. Workhorse gas generator testing at MSFC's Test Stand 116.

The Workhorse GG was tested in phases, beginning with the GG itself in a straight-duct configuration, then incorporating the elbow and U-duct connecting the GG to the fuel turbine - as in the actual flight configuration - to understand the temperature distribution of hot gas arriving at the turbine inlet. The Workhorse GG underwent test conditions simulating the J-2X at 240,000 pound- and 294,000-pound thrust level conditions. The test program had 15 formal objectives. Among those are demonstration of GG pyrotechnic igniter, GG fuel- and oxidizer-side purge, 
injector face heating, injector/chamber compatibility, downselect a GG chamber length and injector element pattern, verification of temperature uniformity of GG combustion products delivered to the fuel turbopump inlet flange and tubine nozzles, GG spontaneous and dynamic combustion stability, provide a validation database for CFD analysis of turbine drive subsystems, provide a test proven WHGG test article to a future powerpack test program.

In addition to the extensive test program conducted by $\mathrm{J}-2 \mathrm{X}$ over the past year, manufacturing is well underway for full J-2X engines, with components at every stage of manufacture for upcoming test articles, like the Powerpack 2 test article turbomachinery, as well as parts for the first full-scale test engines and early flight hardware.

\section{Thrust Oscillation Mitigation}

NASA applied valuable systems engineering lessons learned from tackling pogo vibrations on early launch vehicles to conduct the most comprehensive study of launch vehicle thrust oscillations ever undertaken. These oscillations, created as the first stage burns all of its solid fuel, were identified early in the Ares I design as part of a loads analysis presented during the Ares I October 2007 System Definition Review (SDR). Because the Ares I first stage is based on Shuttle heritage solid rocket motors that are well-characterized, the Ares Projects team discovered the oscillation problem early in the launch vehicle design process, rather than later in the vehicle life cycle as had occurred with pogo on Titan II and Saturn V. This gave the team the opportunity to mitigate the problem in the vehicle as part of the standard NASA design review process, rather than later when technical, schedule, and cost impacts would be greater.

During the June 2009 Technical Interchange Meeting (TIM), the team evaluated (1) data from Ares and Orion structural models and assessments against data from crew situational awareness tests, and (2) updates from industry and NASA teams working on thrust oscillation mitigation devices.

As the baseline mitigation strategy at that time, the team opted to pursue dual plane isolation with two isolator rings: one located at the interstage/frustum interface and another between Orion and the Ares upper stage. The isolation system served to separate the vehicle structural response frequency from the motor forcing frequency, or "de-tune" the vehicle. These rings are designed by the same company that provides passive isolators for commercial payloads.

To provide additional or alternative mitigation, other options were also matured, including Tuned Oscillation Arrays (TOAs), Liquid oxygen (LOX) dampers that use the fundamental physical properties of liquids in the Ares I upper stage tank to dampen vibrations, and Reaction Mass Actuators (RMAs), which use powered springs in the aft skirt to actively cancel out vibration.

The Constellation Program Control Board set a formal baseline for thrust oscillation mitigation during a meeting Dec. 17. Moving forward, the Ares I vehicle design will be updated to include the addition of upper plane C-Spring isolator module and the upper stage fuel tank LOX damper. While evaluations of data from the Development Motor 1 motor test and Ares I-X test flight to date show no problematic thrust oscillation vibrations occurred, the team concluded that incorporating the upper plane C-Spring isolators and LOX damper at this phase of design was a sensible addition. This solution has several advantages:

- Isolator rings are the most mature and simplest solution, and similar rings have isolated payloads from thrust oscillations on more than 17 unmanned flights.

- Adjustable springs provide more flexibility to detune the system as the Ares I and Orion designs mature. The rings have simple designs making them easier and less costly to install, operate, and maintain and less likely to introduce new hazards or problems.

- The design introduces the smallest change to the vehicle height and outer mold line, resulting in fewer and less costly impacts to ground operations infrastructure and guidance, navigation, and control of the vehicle.

- The isolators can be removed with minimal impact if the vehicle design maturity - demonstrated by ground and flight tests-results in detuning.

\section{Pathfinding Future Capabilities for Efficient Design and Operability}

In addition to extensive hardware testing, the Ares Projects Office has continued to work on new manufacturing tools and techniques to streamline the process of manufacturing flight hardware. Using facilities at MSFC as a testbed for the tooling and procedures required to manufacture the Ares vehicles, engineers are able to pass lessons learned and best practices to NASA's Michoud Assembly Facility (MAF) in Louisiana, saving significant expense and schedule when full-scale flight hardware manufacturing begins.

\section{A. Friction Stir Welding}


MSFC has assembled a world-class friction stir welding capability for work on Ares I and future vehicles. The tools in this facility allow for the fabrication of the large structures necessary for launch vehicles stages, using the latest developments in friction stir welding from within NASA and industry partners. Test welding in this facility has been conducted on a variety of manufacturing demonstration articles, including both dome gores and barrel panel sections. This facility also took delivery of common bulkhead domes this year, which have been through their initial inspections and await use in future demonstration articles. Using the lessons learned and tooling development from this facility, two robotic weld tools were delivered to MAF this year.

Current plans call for the entirety of upper stage manufacturing to be performed using friction stir welding. Fusion welding, as is still used in some portions of the Shuttle's external tank manufacturing, can often require extensive repair and additional processing after initial fabrication. By shifting to an entirely friction stir-welded structure, the project should see significantly reduced processing time and cost savings.

\section{B. Multi-axis Machining}

The multi-axis milling machine, equipped with a 2-axis milling head for rotary positioning of the machine tool and a 100 horsepower spindle capable of reaching speeds of $24,000 \mathrm{rpms}$, is the world's largest horizontal multiaccess milling machine for machining large, complex parts, and greatly broadens the horizon of what can be manufactured from metal. A large rotary table is situated in front of the machine. The table, $20 \mathrm{ft}$ in diameter, will be used to manufacture dome-like parts for the Ares I. Spanning over this large rotary table will be a head stock/tail stock capable of swinging parts up to $18 \mathrm{ft}$ in diameter (cylindrical parts of the Ares I). Final checkout and acceptance testing of this milling tool was completed in late 2009, culminating with a test to check each axis for accuracy by milling three different shapes within a tolerance of .0005 of each other to qualify the machine for use. The acceptance test process checked out all of the parameters of the machine for proper function, and the machine has now been certified by MSFC Safety \& Mission Assurance (S\&MA) and the Marshall Engineering Technicians and Trade Support (METTS) contract as fully operational. Ingersoll Machine Tools built this 7-axis milling machine for MSFC and is building a second identical machine for MAF in New Orleans.

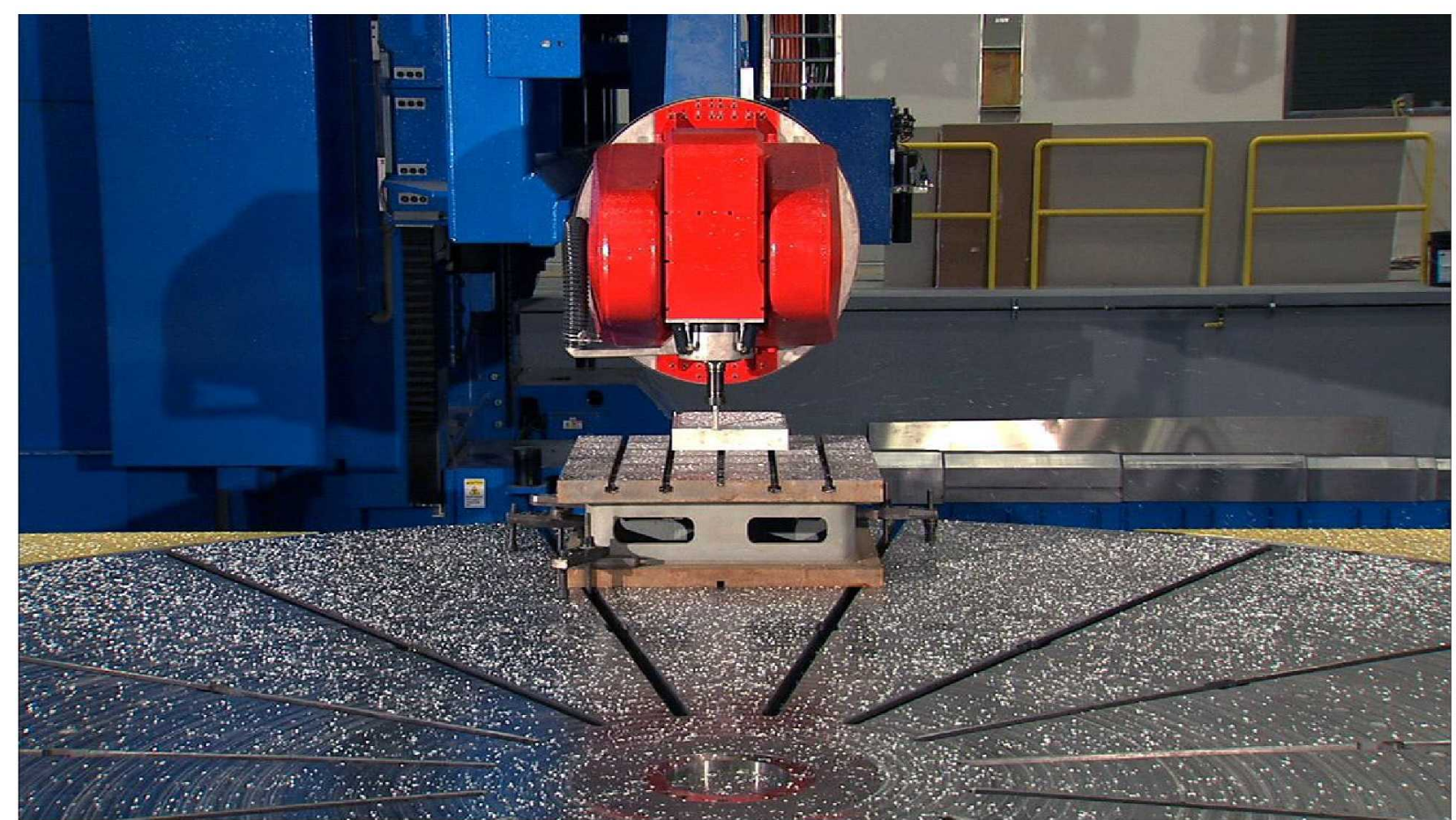

Figure 4. Final acceptance testing of the multi-axis machine tool at MSFC.

\section{Spray-On Foam Insulation Booth}

This facility's purpose is to support the Materials and Processes Lab's efforts in developing replacement Thermal Protection System (TPS) materials and processes. An existing building at MSFC was modified to receive the new Spray-On Foam Insulation (SOFI) booth, which will be used on the Upper Stage TPS. Upper Stage TPS 
material data and process parameters developed in this facility will be transferred to production facilities for implementation. The spray booth installation was completed and a test spray sequence was conducted in December 2009.

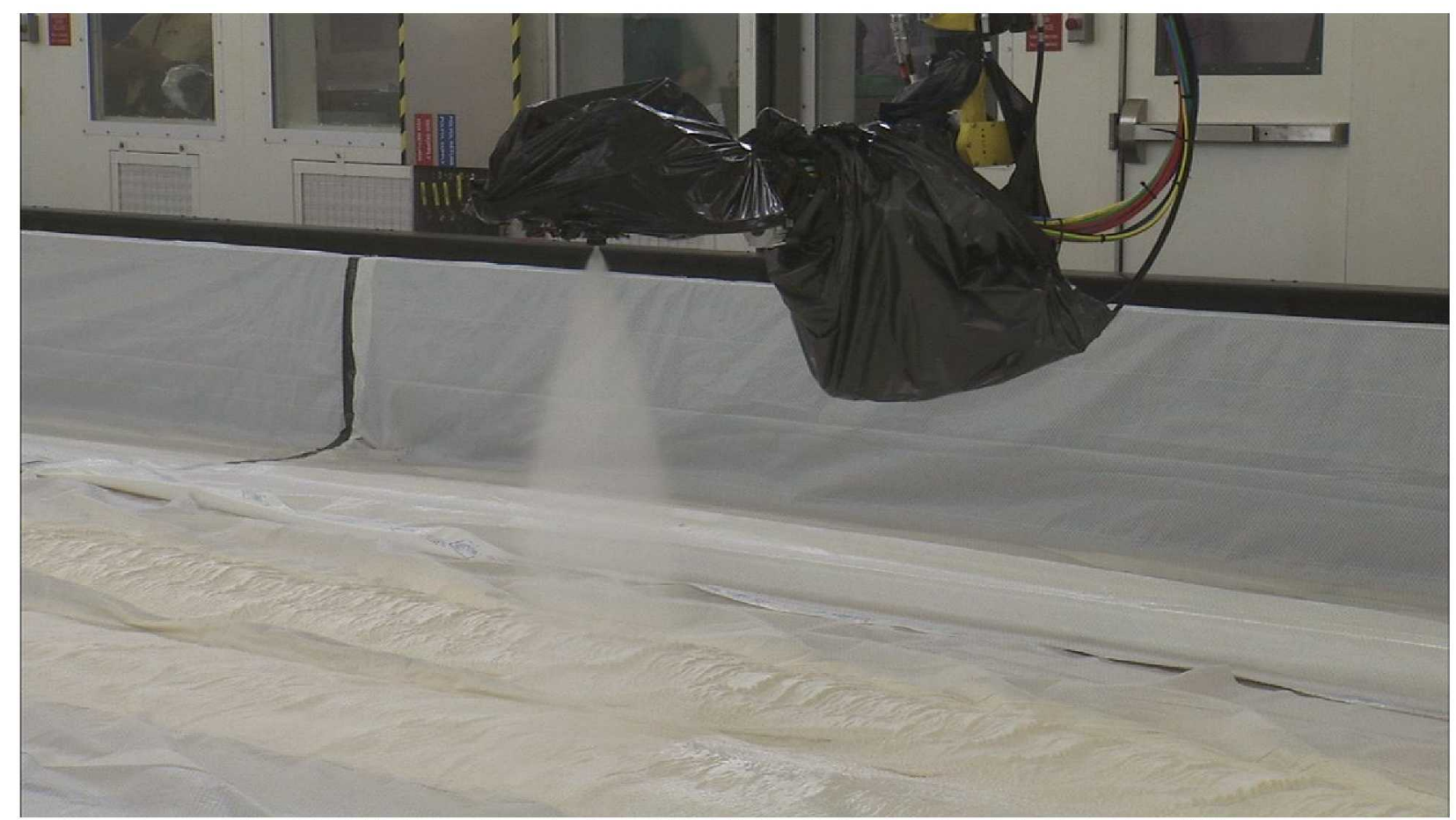

Figure 5. Initial acceptance testing of the SOFI robotic spray booth in December 2009.

Each of these facilities represent a critical capability for the manufacture of launch vehicles, and the pathfinding work at MSFC allows engineers to work out any potential cost or schedule risks in the machines themselves or in the processes related to their use prior to implementation in full-scale hardware production. This provides significant risk reduction for the project, as well as lowering cost for the flight production facilities by giving engineers a chance to provide feedback on the tooling and procedures, prior to procurement and installation. By engineering and testing the tools in this fashion, Ares has embraced lean manufacturing best practices used in other industries, and has provided a template for future lean manufacturing operations at the Agency.

\section{Lessons Learned for Operability}

The launch of the Ares I-X in October 2009 was the culmination of a three-and-a-half year mission incorporating personnel from across the Constellation Program. The flight test successfully achieved all five of its primary objectives, including:

- Demonstrating control of a dynamically similar vehicle using similar flight software;

- Performing an in-flight, first stage separation event;

- Demonstrating the assembly and recovery of a new Ares I-like first stage;

- Demonstrating first stage separation sequencing, and quantifying First Stage atmospheric entry dynamics, and parachute performance; and

- Measuring and controlling the amount of roll torque throughout first stage flight.

In addition to these technical objectives, the launch represented a successful test for the processing crews at Kennedy Space Center, as well as the logistics operations of shipping and integrating a new vehicle configuration. Special arrangements were required to transport these elements to KSC, and stacking operations and facilities had to be modified to accommodate the vehicle architecture. Launch Complex 39B also had to undergo extensive modifications to accommodate the new rocket's design. All the operability lessons learned from this first test flight can now be integrated in the design and operations plans for a full Ares I vehicle. By remaining tightly integrated with the Ares I-X Mission Office throughout the process, Ares Projects Office personnel have gained valuable 
insight into potential logistics and operability issues with the vehicle configuration, and can now incorporate those lessons into future vehicle design work.

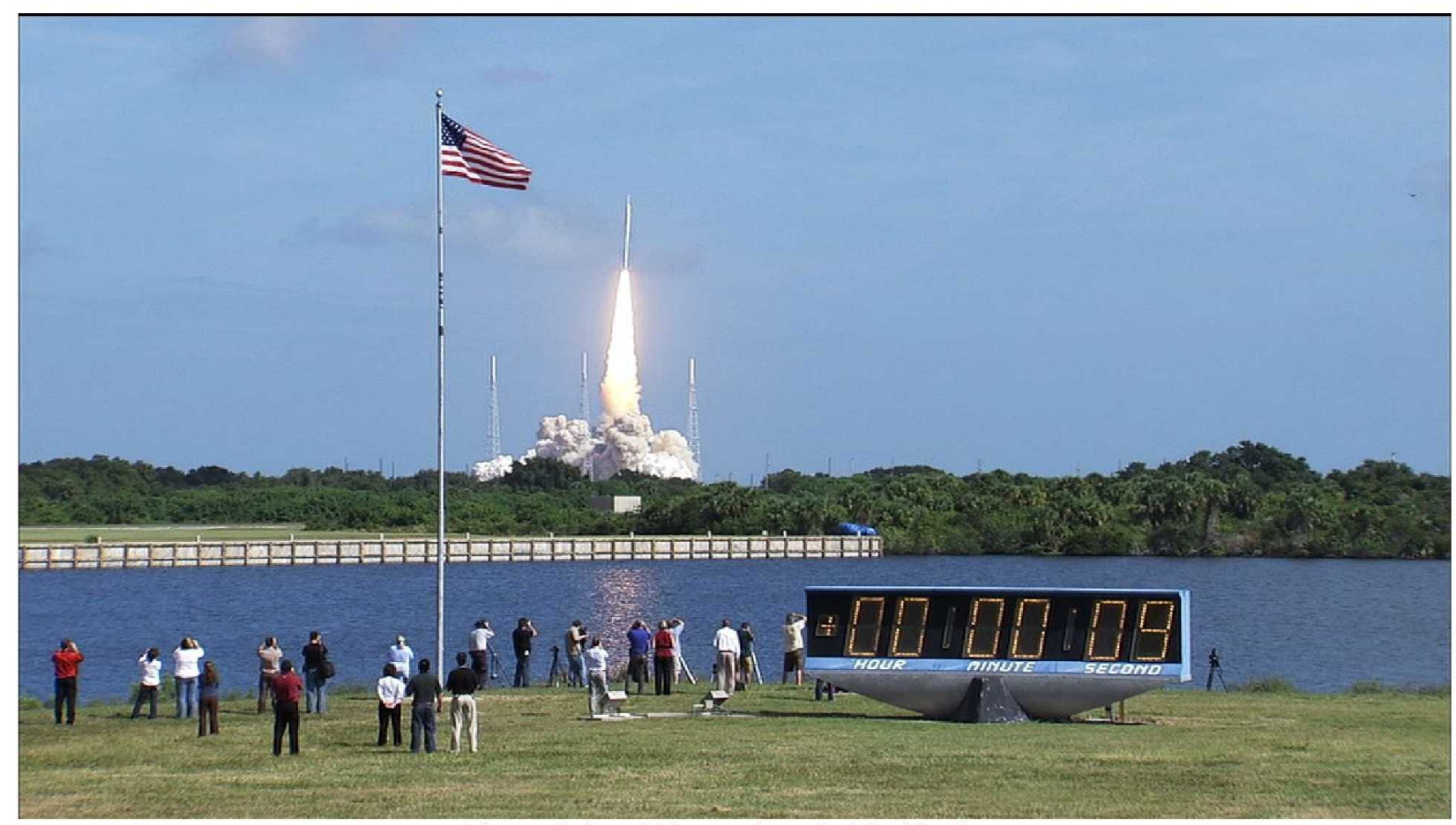

Figure 6. Ares I-X roars into the Florida sky.

\section{Conclusion}

Ares has, since its inception, engineered launch vehicles with an eye towards operability, safety, and affordability. Using full-scale mock-ups of hardware to provide early insight into human factors, performing pathfinding manufacturing testing to inform processes and tooling for flight hardware fabrication, and working closely with ground operations personnel to accommodate for ground support activities and equipment have all played a critical part in the Ares I vehicle design, and will continue to inform vehicle design going forward. These lessons and this design philosophy will likewise inform any future vehicle design work in which the Agency is involved. 


\title{
Space Operations for a New Era of Exploration Launch Vehicles
}

\author{
Daniel J. Davis \\ Ares Projects Vehicle Integration Manager \\ NASA Marshall Space Flight Center
}


- Progress Since Preliminary Design Review

- Vehicle Integration

- First Stage

- Upper Stage

- Upper Stage Engine

$\Delta$ Thrust Oscillation Mitigation

$\triangle$ Pathfinding Manufacturing Capabilities

$\Delta$ Lessons Learned from Ares I-X Flight Test 


\section{Vehicle Integration Progress}

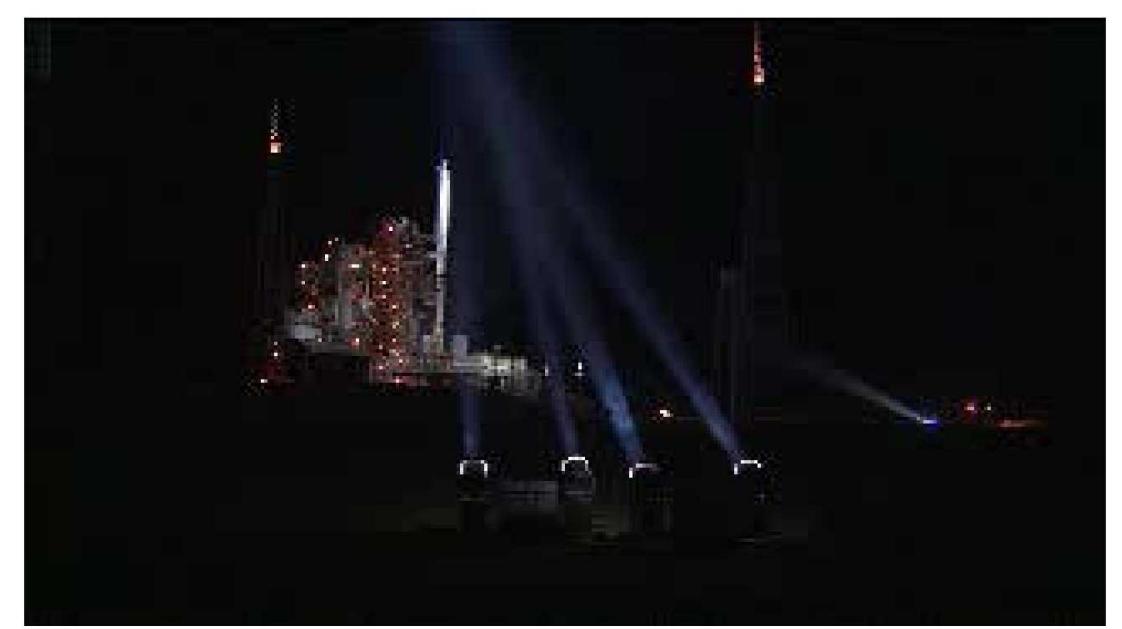

Ares I-X Launch

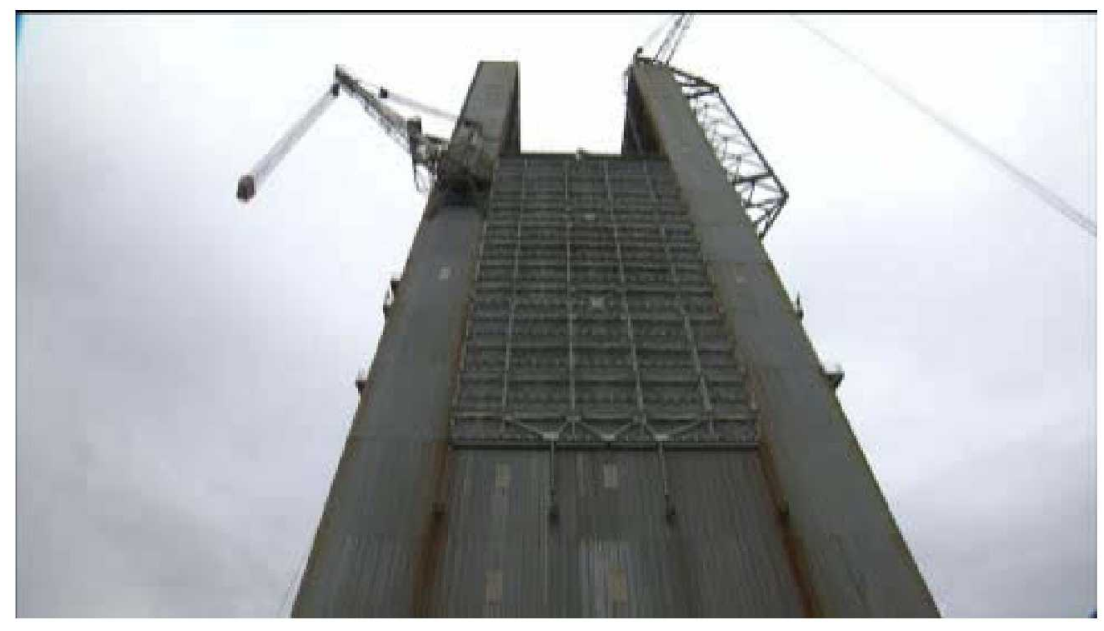

Dynamic Test Stand Refurbishment

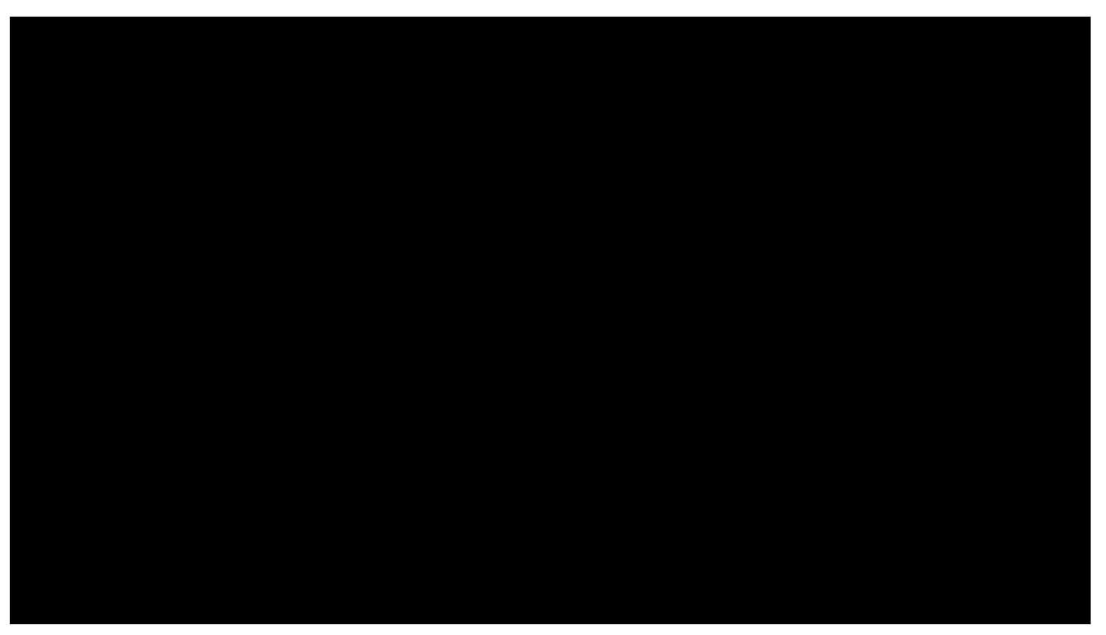

Wind Tunnel Testing 


\section{First Stage Progress}

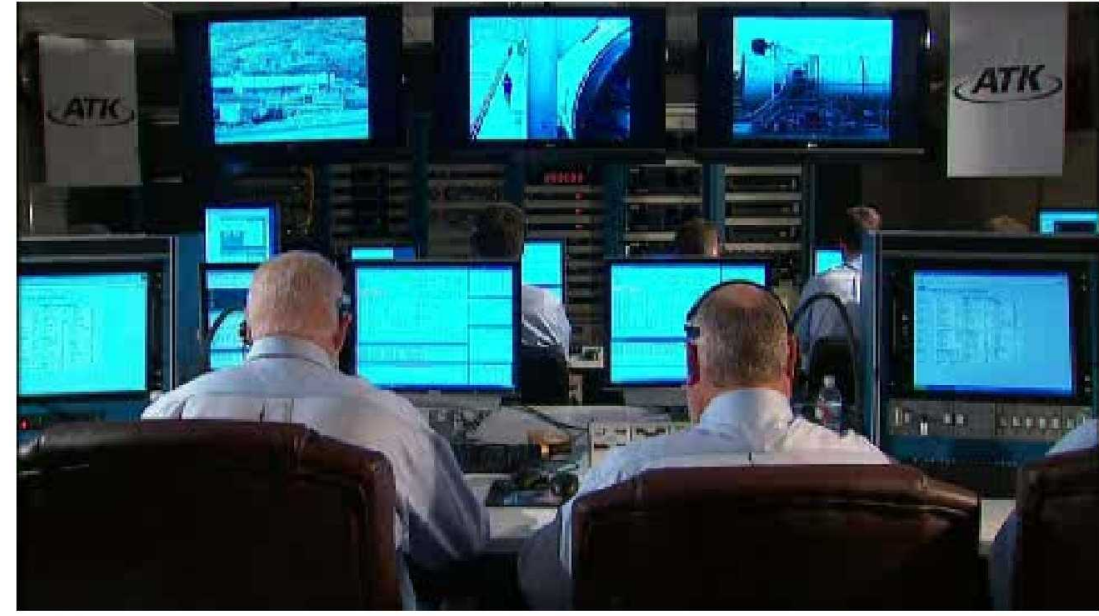

DM-1 Test Firing

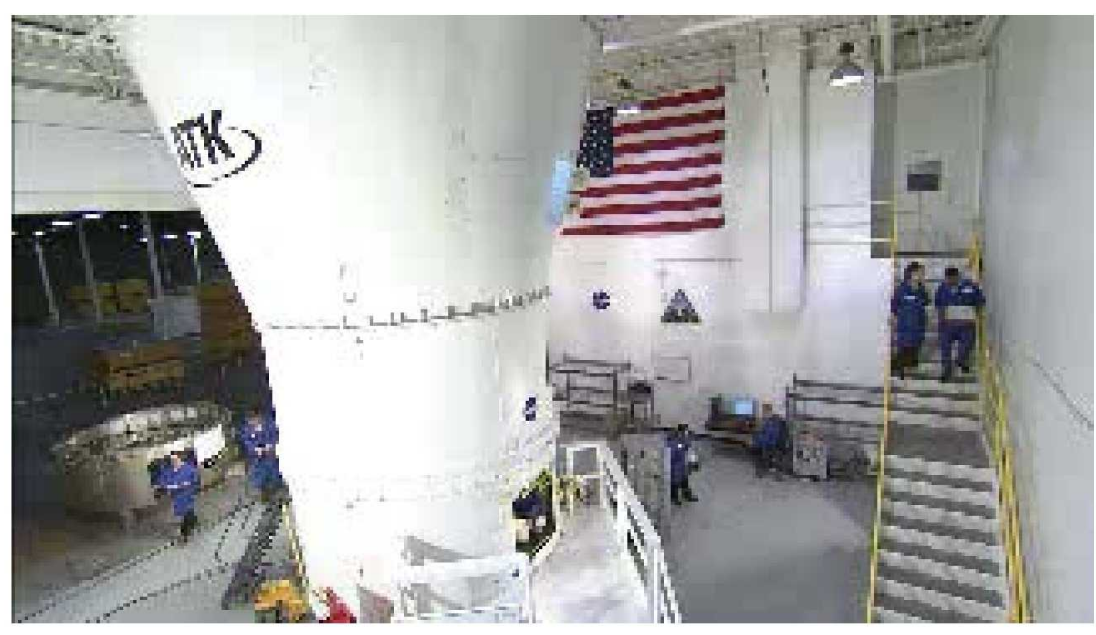

Avionics Full-Scale Mock-up

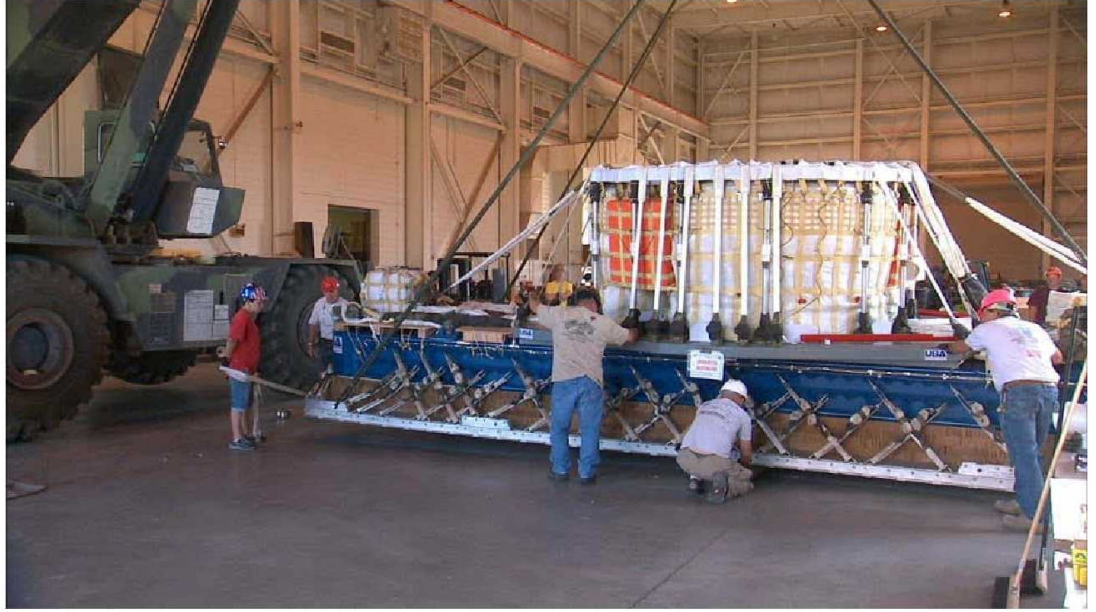

Main Parachute Cluster Drop Test

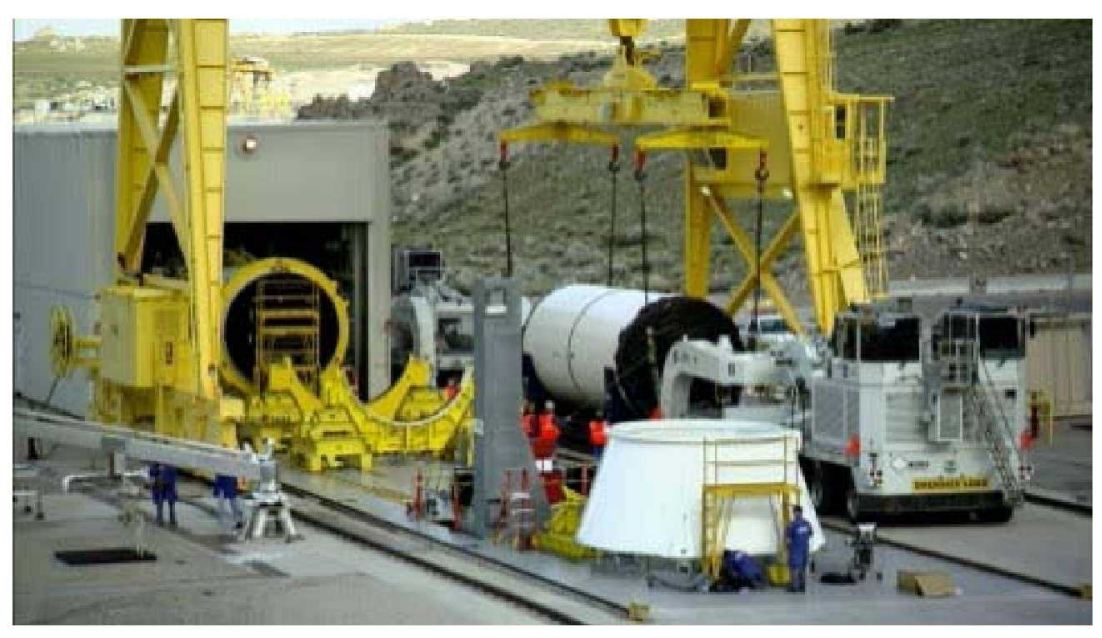

DM-1 Installed at TS 97 


\section{Upper Stage Progress}

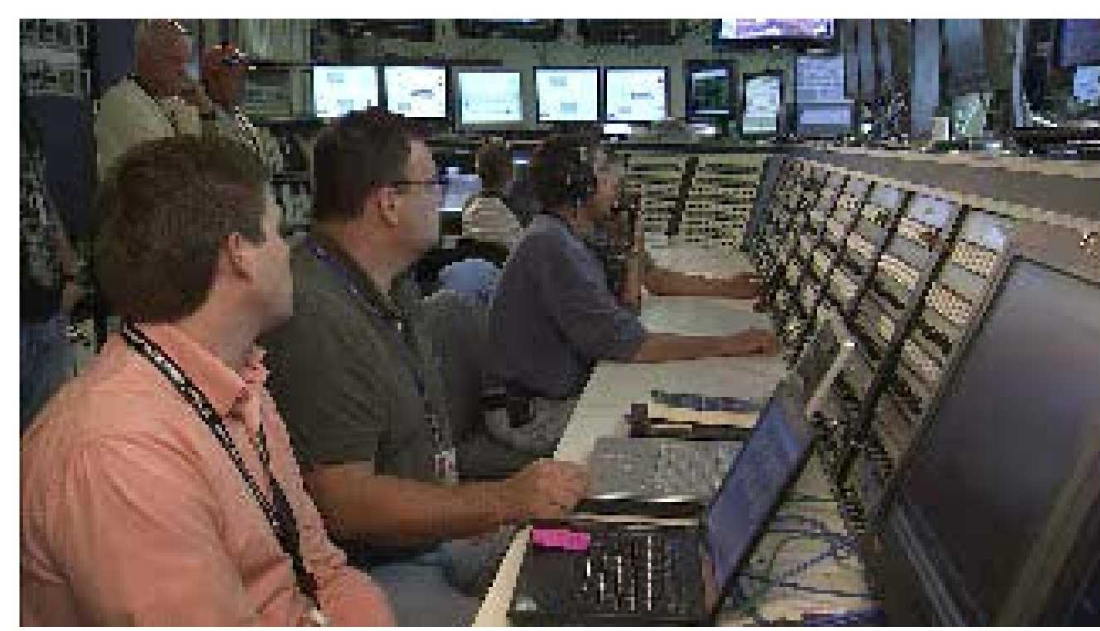

Ullage Motor Hot-Fire

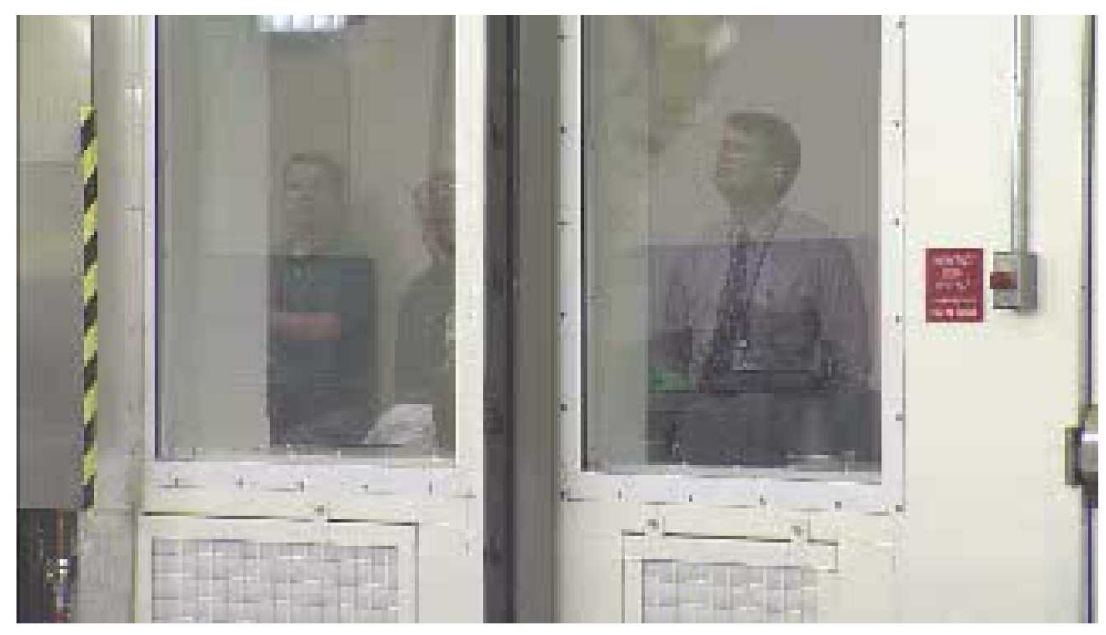

Spray-On Foam Insulation Testing (SOFI)

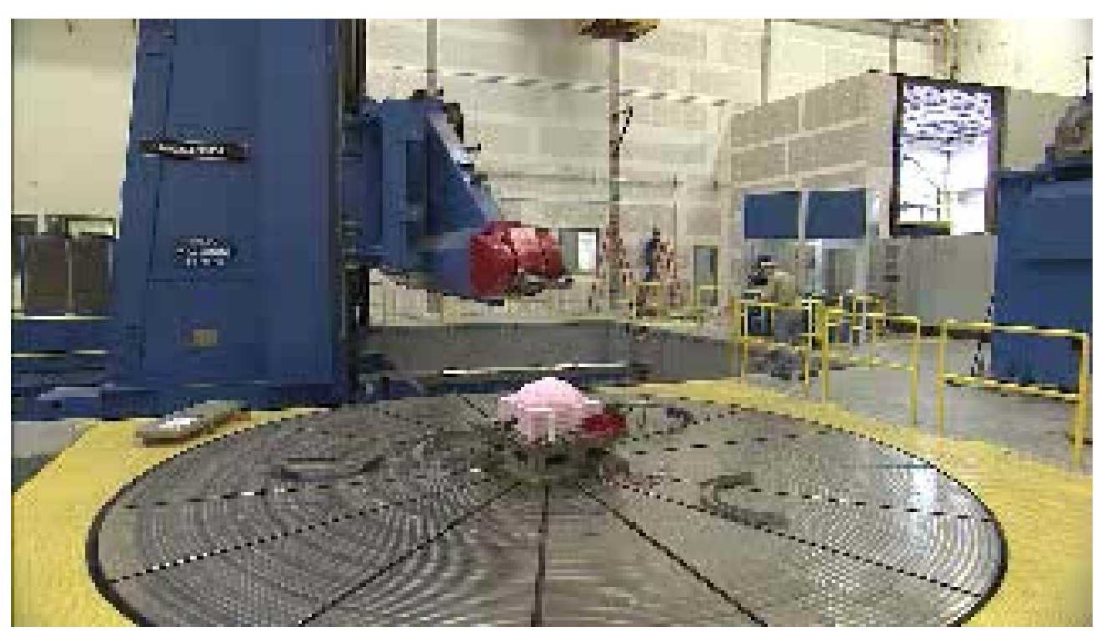

Multi-Axis Milling

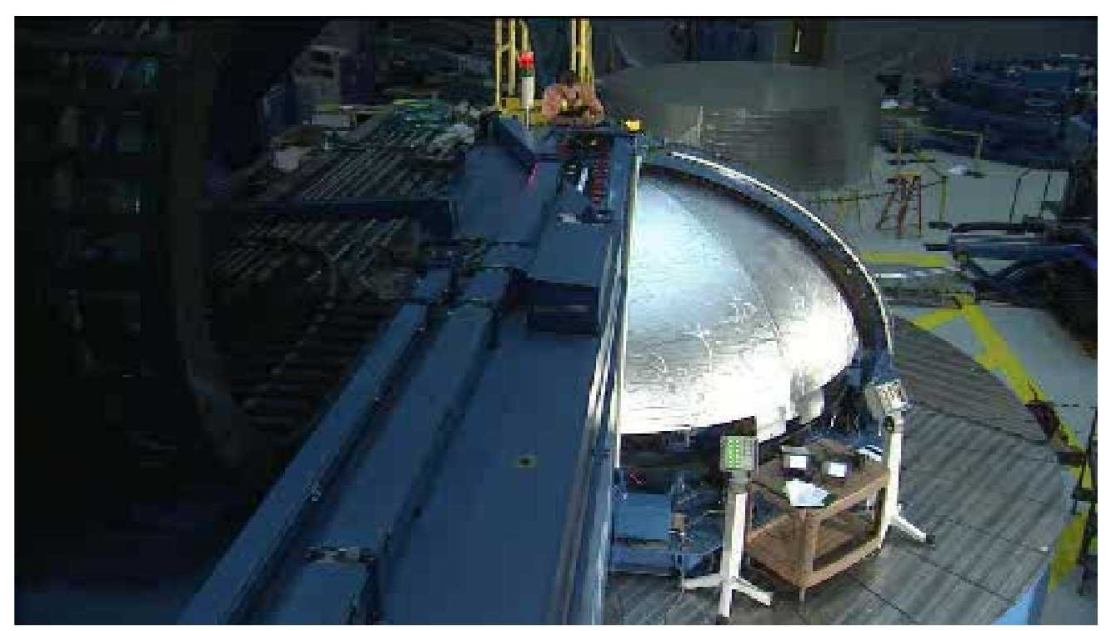

Dome Gore Welding 


\section{Upper Stage Engine Progress}

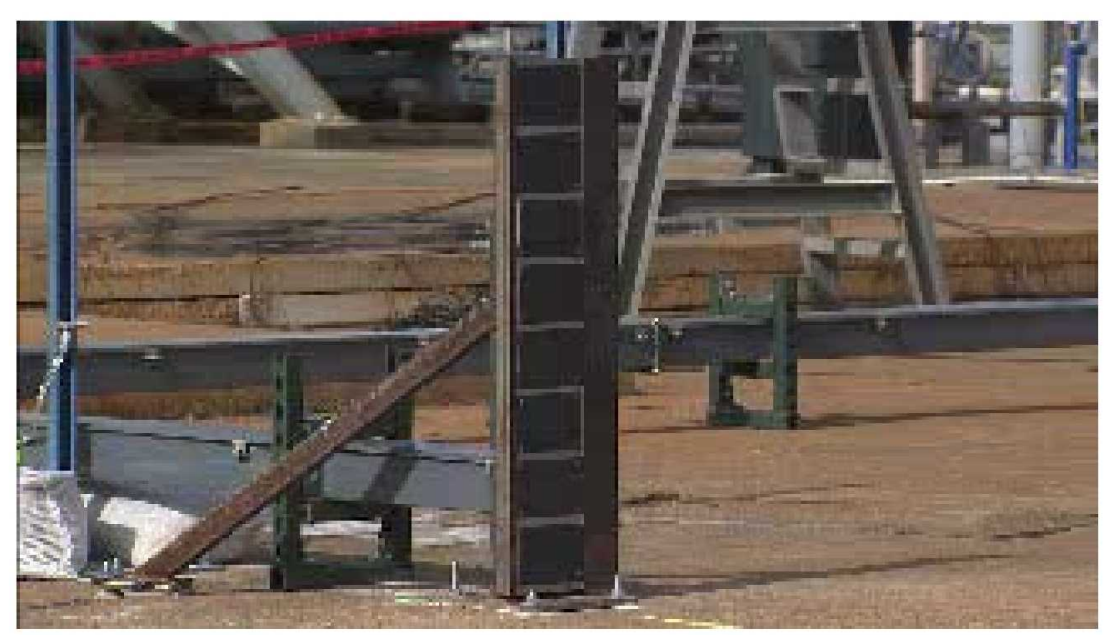

Nozzle Extension Materials Testing

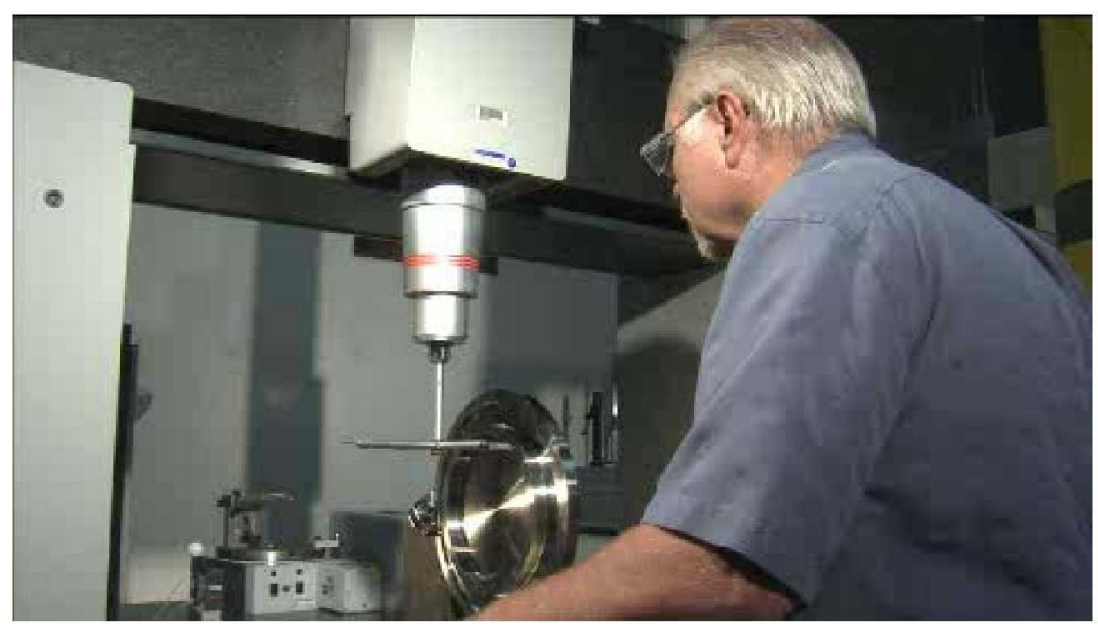

J-2X Component Manufacturing

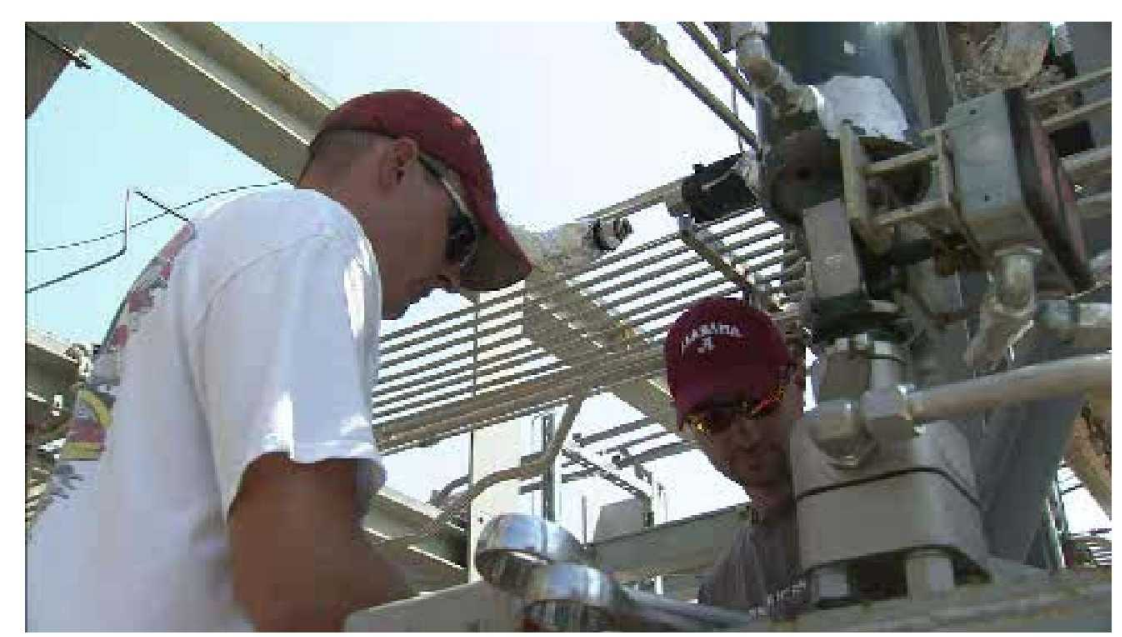

Workhorse GG Testing

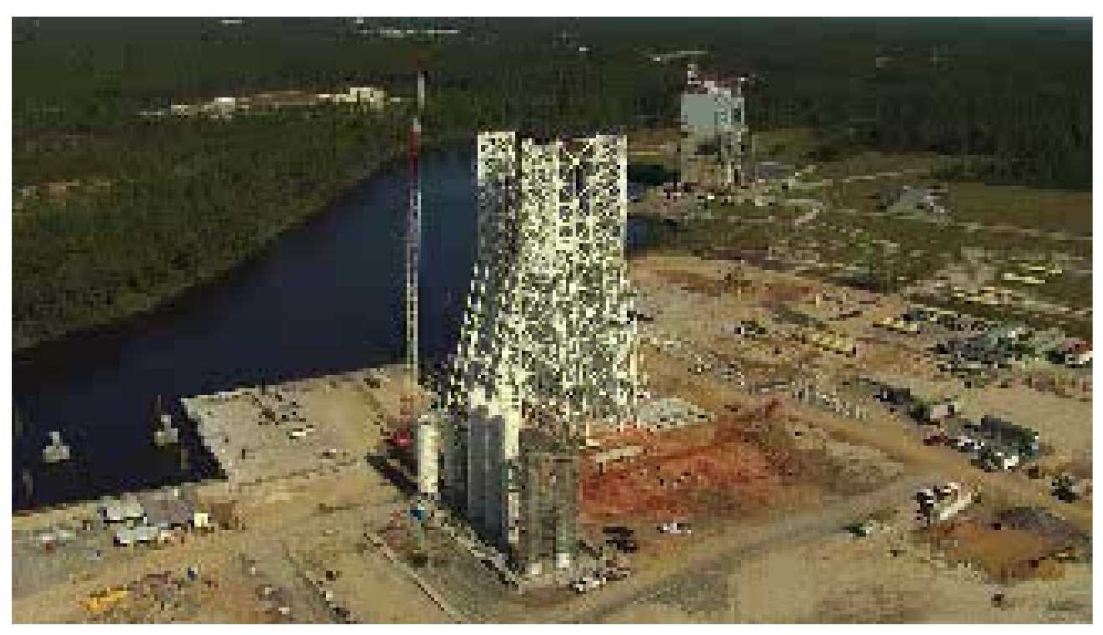

Test Stand A-3 Construction 


\section{Thrust Oscillation Mitigation}

- Baseline design for mitigation set in December 2009.

- Upper plane c-spring isolator ring

- LOX damper

$\Delta$ Introduces the fewest changes to vehicle height and outer mold line.

- Fewer and less costly impact to ground support infrastructure

- Less impact to guidance, navigation, and control of vehicle

$\Delta$ Isolators can be removed if further design maturity results in detuning of vehicle.

Other examined options not carried forward due to complexity and risk.

- Reaction mass actuators

- Tuned oscillation arrays 


\section{Pathfinding Manufacturing Capabilities}

- Initial process/tooling test-bed at MSFC

- Identified ways to streamline manufacturing process

- Lessons learned and best practices carried to Michoud Assembly Facility (MAF), saving expense and schedule for flight hardware

- Friction Stir Welding

- Test welding conducted on dome gores and barrel panels

- Common bulkhead domes received and inspected

- Two robotic weld tools delivered to MAF

- Multi-axis Milling

- Broadens horizon for what can be manufactured from metal

- Will fabricate large, complex parts

- Certified operational in late 2009

- Spray-on Foam Insulation

- Will perform pathfinding tests on both materials and processes used in thermal protection system of upper stage

- Data and parameters developed in this facility will be transferred to MAF for production implementation 


\section{Operability and Ares I-X}

Launch in October 2009 met all five primary objectives.

- Control of dynamically similar vehicle to Ares I

- Performed in-flight first stage separation

- Assembly and recovery of Ares I-like first stage

- First stage separation sequencing

- Measure and control roll torque throughout first stage flight

$\triangle$ Also a successful test of Kennedy Space Center processing crews.

- Logistics of shipping and integration

- Vehicle stacking

- Launch Complex 39B modifications

$\Delta$ Human factors engineering early in Ares I development

- Lessons learned from Ares I-X can be incorporated into future design evolution 


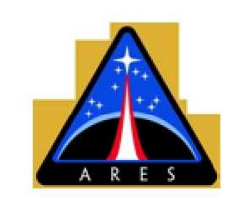

\section{QUESTIONS?}

